Introducing Building Information Modeling Course into a Newly Developed Construction Program with Various Student Backgrounds

Dr. Rui Liu, The University of Texas at San Antonio

Dr. Yilmaz Hatipkarasulu, University of Texas at San Antonio 


\title{
Introducing Building Information Modeling Course into a Newly Developed Construction Program with Various Student Backgrounds
}

\author{
Rui Liu and Yilmaz Hatipkarasulu \\ Department of Construction Science, The University of Texas at San Antonio, San Antonio, TX; \\ Email: rui.liu@utsa.edu,yilmaz.karasulu@utsa.edu
}

\begin{abstract}
Building Information Modeling (BIM) is an emerging trend in construction industry and a desired skill for construction management students as they are preparing for their professional careers. Recent surveys showed that university level BIM education of the architecture, engineering, and construction programs in the United States increased dramatically in the past several years. Structuring a course that would properly address the learning needs of students with different levels of technology skills and construction experience is a considerable challenge. This paper presents the introduction of a BIM course to a construction management program with a diverse student body. The course is structured as a lecture-lab combination where the fundamental concepts and implementation issues are discussed in the lecture portion. In the lab sessions, the students are asked to complete individual projects and present them in different formats. The purpose of this paper is to provide a sample structure to deliver BIM content. Feedback from the students, instructor observations, and recommendations for the computer exercises are also included in the paper.
\end{abstract}

\section{Introduction}

As Building Information Modeling (BIM) becomes a standard practice in the ArchitectureEngineering-Construction industry, many universities and colleges offering a construction related program started to integrate BIM concepts and skills into their programs ${ }^{1}$. Several university level BIM courses with different educational approaches were developed and implemented in the recent years. Based on the survey distributed to members of Associate School of Construction, as of 2008 , less than $1 \%$ of the construction programs had a stand-alone BIM course while $9 \%$ incorporated BIM as part of the existing courses ${ }^{2}$. By the year $2011,56 \%$ of all surveyed programs offered BIM courses ${ }^{3}$. Becerik-Gerber et al. noted the lack of adequately trained BIM personnel was the major reason hindering BIM adoption in the Architecture-Engineering-Construction industry ${ }^{3}$. By 2013, $54 \%$ of the programs had dedicated and fully developed BIM class included in their curriculum while $52 \%$ claimed BIM content was embedded in conventional courses ${ }^{4}$. It is important to note that some programs have more than one BIM courses. The same study also suggested that partnership might be the solution to advancing BIM education as well as BIM staff acquisition in the Architecture-EngineeringConstruction industry ${ }^{4}$. The process of BIM created new career paths for young professionals ${ }^{6}$. New positions such as "BIM engineer/BIM manager" became a choice for current college graduates and may become their future career path. While the industry, especially medium to large size contractors, is progressively taking advantage of BIM technology, structured BIM education at university level is slowly progressing. It is critical to address this need with an efficient and effective course structure while boosting the student's technical capabilities. 
This paper presents the introduction of a BIM course to a construction management program with a diverse student body. In the University of Texas at San Antonio construction program, more than half of the students maintain half-time or more employment while attending school and the student body shows a large variance in computer skills. The new BIM course content was designed to integrate the industry experience of the students to support and enhance understanding of spatial relationships, interoperability and communication problems. The course was structured as a lecture-lab combination where the fundamental concepts and implementation issues were discussed in the lecture portion. The laboratory portion of the course uses two different approaches to ensure the fundamental software skills as well as a clear understanding of the implementation challenges. The students were asked to complete individual projects in the first half of the course. The project consists of a small residential building which enables students to create a model from the beginning to the end in a limited amount of time. Different methods to address possible conflicts in design and construction are discussed and simulated in this process.

The purpose of this paper is to provide a sample structure to deliver BIM content to serve different needs of the students at different computer skill level and various industry experiences. This structure can also be adapted for BIM education for experienced industry practitioners. Feedback from the students, instructor observations, and recommendations for the computer exercises are also included in the paper.

\section{Course Components and Grading Structure}

The "BIM for Construction Management" course was offered as three-credit hour elective course. The target audience was mainly senior and junior construction majors, who already completed basic construction courses including plan reading, estimating, scheduling, and project management. Since it was the only BIM course in the curriculum at the time, the course was designed to cover a wide variety of BIM topics including clash detection and constructability, design and visualization, model based quantity take-off (QTO) and estimating, and 4D scheduling.

The course assessment consisted of one midterm exam (10\% of the grade), one final exam (10\% of the grade), homework projects ( $30 \%$ of the grade), quizzes (10\% of the grade), and a term project with two milestones ( $40 \%$ of the grade). As all the lecture and lab sessions were performed in a computer lab, students had access to a working computer throughout the semester. Exams and quizzes were conducted online through Blackboard Learn 9.1 in multiple choice and open ended question formats. Considering the hands-on experience required excelling in the use of the computer software packages, the homework and project assignments carried a larger weight of the final grade.

The software platforms covered in this course included Revit Architecture, Revit Structure, Revit MEP and Navisworks. Other complimentary software packages such as MS Excel, Sketch-up and MS project, P6 were also utilized but no specific instructions were provided for these software packages.

Each course session started with a lecture and followed by lab exercises. The lecture portion included introduction of the BIM concepts, execution plans, implementation, case studies, and 
demonstration of specific steps to use the software. The lab portion provided students with hands-on skills. In the lab sessions, the first half of the semester focused on Revit architecture, structure, and MEP, with the purpose of providing basic modeling skills, understanding of the database structures as well as the process of coordination among different trades in a typical construction project. The second half of the semester focused on the trade coordination in Navisworks, clash detection, 4D scheduling, and color coding different trades with different platforms. Figure 1 shows a sample student work that includes architecture, structure and MEP elements completed in the first half of the course. Since the course was offered as a construction course, grading of the models focused on the modeling of required objects and accuracy rather than the design value.

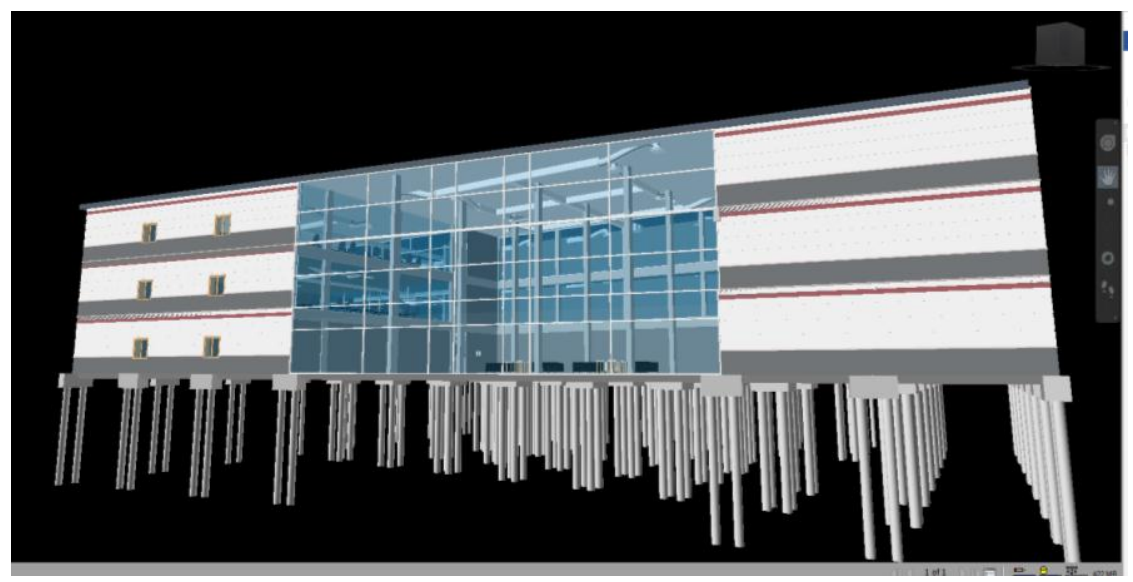

Figure 1. Sample Student Work

The term projects were structured in two milestone assignments. The milestones asked students to complete particular segments of the project model and these models were presented in two different formats. The assignment criteria provided a flexible structure where the students were encouraged to explore different functions of the software packages. Figure 2 shows sample screenshots from the video presentation of a student's project.

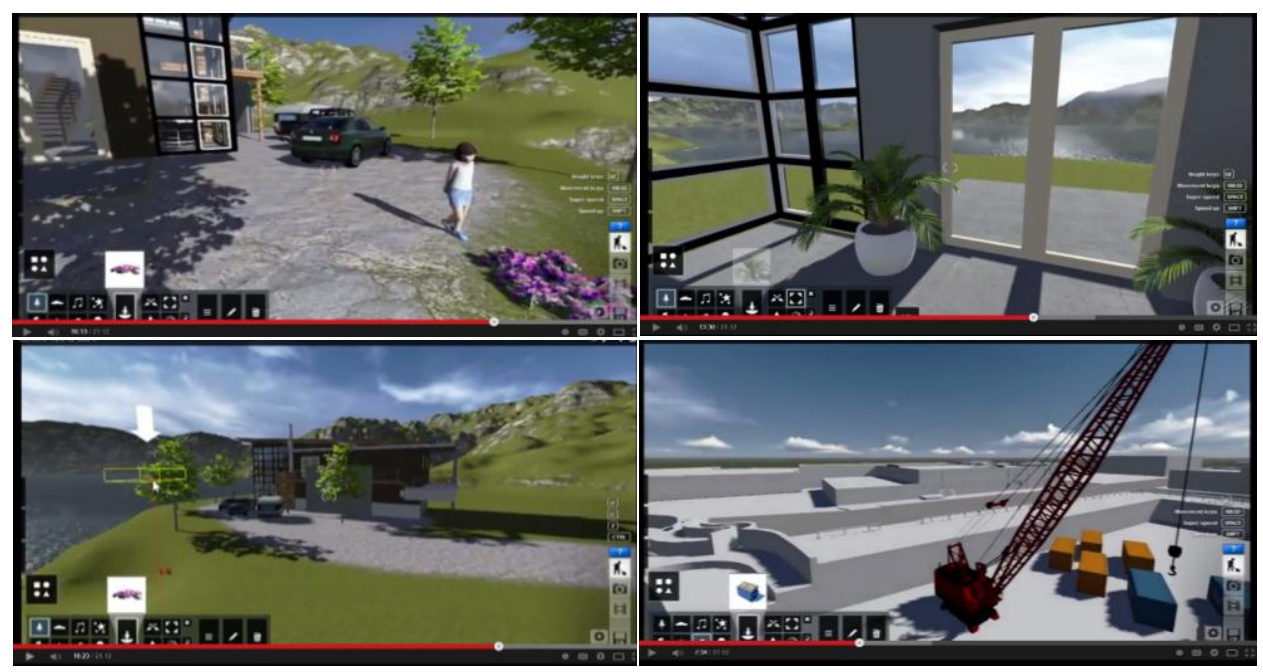

Figure 2. Video Screenshots from Student Model Presentations 
The differences in the computer skill level of the students were clearly observed in these assignments. While all of the students were able to include different disciplines, QTO and estimating, clash detection, and 4D scheduling (using P6 or MS project) functions into their models, some students created site logistic plans using sketch up and realistic animations using Lumion.

\section{Student Evaluations and Feedback}

At the end of the semester, two separate evaluations were performed to measure the content and delivery of the course. A total of 25 students were registered for the course in two separate sections. The students enrolled in the class were 64\% Hispanic, $8 \%$ female, $45 \%$ registered to 12 or less semester credit hours and $40 \%$ registered to 15 or more credit. The first evaluation was a standard online student evaluation performed for every course offering at the university. A response rate of $52 \%$ (13 out of 25 students) was recorded for the online evaluation. The evaluation questions and the combined results are presented in Table 1.

Table 1. Combined Student Evaluation Results

\begin{tabular}{|c|c|c|}
\hline & \multicolumn{2}{|c|}{ Student Evaluation } \\
\hline & Scale & Combined Score \\
\hline $\begin{array}{l}\text { I was very satisfied with the educational experience this } \\
\text { instructor provided. }\end{array}$ & $\begin{array}{l}\text { Strongly Agree }=5.00 \\
\text { Strongly Disagree }=0.00\end{array}$ & 4.2 \\
\hline I felt that my participation in class discussions was welcomed. & $\begin{array}{l}\text { Strongly Agree }=5.00 \\
\text { Strongly Disagree }=0.00\end{array}$ & 4.6 \\
\hline The instructor promoted critical thinking about course concepts. & $\begin{array}{l}\text { Strongly Agree }=5.00 \\
\text { Strongly Disagree }=0.00\end{array}$ & 4.1 \\
\hline The instructor kept students informed of their progress. & $\begin{array}{l}\text { Strongly Agree }=5.00 \\
\text { Strongly Disagree }=0.00\end{array}$ & 4.5 \\
\hline The instructor's presentations were generally thought provoking. & $\begin{array}{l}\text { Strongly Agree }=5.00 \\
\text { Strongly Disagree }=0.00\end{array}$ & 3.9 \\
\hline This course challenged me intellectually. & $\begin{array}{l}\text { Strongly Agree }=5.00 \\
\text { Strongly Disagree }=0.00\end{array}$ & 4.1 \\
\hline My overall rating of the course is: & $\begin{array}{l}\text { Excellent }=5.00 \\
\text { Poor }=0.00\end{array}$ & 4.0 \\
\hline My overall rating of the teaching of this course is: & $\begin{array}{l}\text { Excellent }=5.00 \\
\text { Poor }=0.00\end{array}$ & 4.0 \\
\hline
\end{tabular}

As presented in Table 1, the course received an overall rating of 4.0/5.0 while the questions related to the instruction of the course varied from 3.9 to 4.6. The second anonymous evaluation was an in-class survey that asked for direct feedback from the students. A $100 \%$ response rate was recorded for this evaluation. A sample of the survey responses on the course include (verbatim from the survey forms): 
- "this course was overall an awesome learning experience and what I have taken from this course I hope to use one day in my construction career. I wish we had more time to learn the software more in depth..."

- "Overall this class was fun and easy to keep up with..."

- "more samples or drills for practice..."

- One of my suggestion "have more homework and optional activities...."

- "I would suggest more class time. The class is very detailed in how to produce a product that can be used out in real world applications. To be able to transfer our knowledge we have gained in this course when we use this after completion would be challenging. I found myself rushed very often throughout the semester due the time constraint we had during lecture... I feel I have obtained the foundation and understanding of BIM but know that there is still much more to learn and would enjoy doing so if I had the chance."

- "have separate classes for software, such as one individual class for Revit Architecture, one class for Revit Structure, one class for Revit MEP, and one class for Navisworks manage"

- "My suggestion for this course is to be a little more slower pace, so that is may allow more time to digest and apply the information that is being taught"

- "too fast and too much information"

- "this course should be split in to two or more classes..."

- I would suggest that the class be taught at a slightly slower pace...

These comments clearly demonstrate the diverse level of computers skills and experience of the students. While some comments suggest slowing down, others were asking for more exercises and examples. Some of the comments also highlighted logistical issues related to the course.

- "Some students are not fortunate enough to have computers/laptops, or the lab hours given are not sufficient enough"

- "Have a smaller group of students per class..."

- "I think there could be some collaboration between the Construction Science students and the Architecture students..."

Even though the software packages were available from Autodesk without any cost to the students, student's personal laptops were not always capable of handling the four BIM software packages. As a result, students still preferred to go to the lab to complete their work.

\section{Instructional Observations and Recommendations}

The observations and recommendations from the first offering of the BIM course at the University of Texas at San Antonio can be summarized under three groups.

1. Don't make every assignment required

It is extremely important to manage the expectations from the students at a realistic level while providing optional exercises to maintain student interest. Since more than half of the students had full time/part time jobs while they were taking this course, dedicating the time to complete the models was a challenge for some of the students. To balance the 
learning needs without sacrificing the quality of the course, some flexibility should be given in homework and project assignments. For example, some required homework and term projects could be assigned at a slower pace and some bonus assignments and projects can be made available for students who can obtain the skills faster than others.

2. Supplemental video tutorials may help

The instruction of the computer applications depended heavily on the demonstrations during the lab hours in addition to the procedure sheets provided for each assignment. As the applications become more complex (especially in the second half of the class), the practically of written procedure sheets decreased significantly. When a student falls behind in-class or misses a class demonstration, it is extremely difficult to catch up with the assignment. In the age of You-Tube, students would be comfortable supplementing the instruction with video tutorials however; it may also lead to student to a false sense of comfort and depreciate the value of in-class demonstration. Our initial sense is that, for the special student body at the University of Texas at San Antonio, it may be helpful to provide some video tutorials to supplement the in-class instructions.

3. Arrange a reasonable pace of instruction and maintain student interest

It is important to keep in mind that not every construction major is going to become a "BIM Manager" in their professional career. There will be a small group of students that have high level of computer skills and a passion for the BIM process which will perform better than the others. Similarly, there will always be a group of students with below average computer skills which will excel in other career paths in construction industry. For a computer lab-based course, it is critical to arrange a reasonable pace of instruction which would challenge the students with below average computer skills rise to a higher level of performance while maintaining the interest of the rest of the class. Maintaining the pace of instruction at the level of average student would address this challenge. It is also important to provide additional development opportunities for the skilled students to cultivate the next generation of the "BIM Managers."

\section{Summary and Conclusions}

Building Information Modeling (BIM) is an emerging trend in construction industry and a desired skill for construction management students. Recent surveys showed that university level BIM education of the architecture, engineering, and construction programs in the United States increased dramatically in the past several years. The computer application requirements of this subject makes it challenging to structure a course that addresses the learning needs of the students while maintaining their interest.

This paper presented the experiences from the first time offering of a BIM course in a relatively young construction program with a diverse student body. The subjects covered in this standalone course, grading structure, content delivery methods, term projects, student feedback, and lessons learned from the first year are discussed in this paper. One of the significant challenges was estimating the time requirements for the homework and project assignments. As it would be 
expected from the first time offering of any course, the instructor initially set relatively ambitious goals for the student production. Once the computer skills and production rate of the students became clear at the first half of the class, an adjustment was made to the term project to better align with the students' capabilities. Regardless of their performance in the class, students very clearly understand the importance of BIM in today's construction industry and appreciate its value for their careers.

\section{References}

1. Sacks, R., and Pikas, E. (2013). "Building information modeling education for construction engineering and management. I: Industry requirements, state of the art, and gap analysis." Journal of Construction Engineering and Management, 139(11).

2. Sabongi, F. J. (2009). "The Integration of BIM in the Undergraduate Curriculum: an analysis of undergraduate courses." Proc., 45th Annual Conference of ASC, Gainsville, FL.

3. Becerik-Gerber, B., Gerber, D. J., and Ku, K. (2011). "The pace of technological innovation in architecture, engineering, and construction education: integrating recent trends into the curricula." Electronic Journal of Information Technology in Construction, 16, 412-431.

4. Wu, W., and Issa, R. R. (2013). "BIM Education and Recruiting: Survey-Based Comparative Analysis of Issues, Perceptions, and Collaboration Opportunities." Journal of Professional Issues in Engineering Education \& Practice.

5. Uddin, M. M., and Khanzode, A. R. (2013). "Examples of How BIM can Enhance Career Paths in Construction." Practice Periodical on Structural Design and Construction.

6. Pikas, E., Sacks, R., and Hazzan, O. (2013). "Building information modeling education for construction engineering and management. II: Procedures and implementation case study." Journal of Construction Engineering and Management, 139(11). 